\title{
Hemşirelerin İletişim Becerileri ve Öfke Yönetimlerinin Belirlenmesi
}

\author{
Arzu Aydoğan, Birgül 0̈zkan²®
}

'Gülhane Eğitim ve Araştırma

Hastanesi, Eğitim Birimi, Ankara, Türkiye

${ }^{2}$ Ankara Yıldırım Beyazıt Üniversitesi, Sağlık Bilimleri Fakültesi, Psikiyatri Hemşireliği Anabilim Dalı, Ankara, Türkiye

Arzu Aydoğan, Dr. Birgül Özkan, Doç. Dr.

Illetişim:

Dr. Arzu Aydoğan

Gülhane Eğitim ve Araştırma Hastanesi, Eğitim Birimi, Ankara, Türkiye

Tel: +90 5056574254

E-Posta: aaydogan80@gmail.com

Gönderilme Tarihi : 30 Ağustos 2018

Revizyon Tarihi : 05 Mart 2019

Kabul Tarihi : 25 Mart 2019
ÖZET

Amaç: Hemşirelerin iletişim becerileri ve öfke yönetimleri arasındaki ilişkinin belirlenmesi amaçlanmıştır.

Gereç ve Yöntem: Bu çalışma, tanımlayıı bir araştırmadır. Çalışma, Ankara/Türkiye'de bir eğitim ve araştırma hastanesinde Mart- Haziran 2017 tarihleri arasında 144 hemşire ile yapılmıştır. Çalışmanın verileri, sosyo-demografik veri toplama formu, Illetişim Becerileri Envanteri (IBE) ve Sürekli Öfke ve Öfke Ifade Tarzı Ölçeği (SÖÖTÖ) kullanılarak toplanmıştır. Verilerin analizi, SPSS 22.0 paket programında yapılmıştır.

Bulgular: Hemşirelerin iletişim toplam puan ortalamaları 161,74 $\pm 13,71$ olarak belirlenmiştir. İBE'nin alt ölçekleri olan zihinsel alt boyut puan ortalamaları $55,81 \pm 5,99$; duygusal alt boyut puan ortalamaları $52,72 \pm 5,34$ ve davranışsal alt boyut puan ortalamaları da $53,20 \pm 4,98$ olarak bulunmuştur. Sö̈̈TÖ'nin alt ölçek puan ortalamaları ise; sürekli öfke puan ortalamaları $17,18 \pm 4,11$; içe yöneltilen öfke puan ortalamaları $14,54 \pm 2,92$; dışa yöneltilen öfke puan ortalamalaII 13,50 $\pm 2,98$ ve öfke kontrolü puan ortalamaları da $21,36 \pm 3,74$ olarak belirlenmiştir.

Tartışma ve Sonuç: Çalışmaya katılan hemşirelerin iletişim becerileri düzeyinin ortalamanın üzerinde olduğu belirlenmiştir. Ayrıca, hemşirelerin sürekli öfke ve öfke ifade tarzlarının iletişim becerileri üzerinde olumsuz etkisi olduğu saptanmıştı. Bu çalışmanın sonuçları, hemşirelere düzenli aralıklar ile öfke yönetimi eğitimi planlanmasının onların iletişim becerileri üzerinde olumlu etki oluşturacağını göstermektedir.

Anahtar sözcükler: Hemşire, iletişim becerileri, öfke

\section{DETERMINATION OF ANGER MANAGEMENT AND COMMUNICATION SKILLS OF NURSES}

\section{ABSTRACT}

Objective: It was conducted to determine communication skills scores and anger management points of nurses in this study.

Materials and Methods: Conducted as descriptive, this research was performed in a Training and Research Hospital between March and June 2017. The sample of the research included 144 nurses working in the hospital and accepted to participate in the study between the specified date. The data were collected by means of socio-demographic data collection form, Communication Skills Inventory (CSI) and State Anger and Anger Expression Scale (SAAES). The analysis of data was carried out in SPSS 22.0 package program.

Results: When the score averages that nurses get from the scales are considered, communication total score averages were found as $161.74 \pm 13.71$; mental sub-dimension score averages which are the sub-scales of CSI, as $55.81 \pm 5.99$; emotional sub-dimension score averages as $52.72 \pm 5.34$ and behavioral sub-dimension score averages as $53.20 \pm 4.98$. Sub-dimension score averages of SAAES were found as follows: state anger score averages were 17.18 \pm 4.11 ; intrinsic anger score averages were $14.54 \pm 2.92$; extrinsic anger score averages were $13.50 \pm 2.98$ and anger control score averages were $21.36 \pm 3.74$.

Discussion and Conclusion: It was found out that the communication skill levels of the nurses participated in the research were above the average. State anger and anger expression of nurses have an influence on their communication skills and within this direction, it is considered that providing anger management training to nurses at regular intervals will be influential on their communication skills.

Keywords: Nurse, communication skills, anger 
$\mathrm{H}$ emşirelik, sağlıklı/hasta bireylerin gereksinim duyduğu sağlık bakımını vermeyi amaçlayan ve bu amaca yönelik olarak veri toplayan, hedefleri belirleyen, belirlediği hedefler doğrultusunda girişimler planlayarak girişimleri uygulamaya geçiren bir meslektir (1). Profesyonel bir hemşirenin görevi, hemşirelik mesleğinin amacını yerine getirecek şekilde hasta ile amaçlı bir etkileşimi planlamak, yönlendirmek ve rehberlik etmektir (2).

Illetişim, kişilerarası ilişkilerde anahtar görevi görmektedir. Duyguların, düşüncelerin, beklentilerin ve gereksinimlerin insanlar arasında karşılıklı olarak iletildiği bir süreç olarak tanımlanan iletişimin $(3,4)$, hemşirelik mesleğinde özel bir yeri vardır. Hemşireler hastalarının problemlerini tanımlamada, çözmede ve bireylere verilen sağlık eğitiminde iletişim tekniklerini kullanırlar (5). Hasta-hemşire iletişimi, hastanın sağlık ihtiyaçları değiştikçe değişebilen ve hemşirelerin hastalarına olumlu duygular ve davranışlar gösterebildiği dinamik bir süreçtir (6). Bunun yanı sıra, hasta ile çalışan tüm sağlık profesyonellerinde olduğu gibi hasta- hemşire iletişiminde de bazı zorlukların yaşanması söz konusu olabilmektedir. Bireyler arasında yaşanan ve iletişimi engelleyen zorlukların, hekim veya hemşire gibi sağlık profesyonellerinden ya da hastadan kaynaklanabileceği gibi, hastanın tedavisinin başarısızlığından, sağlık sistemindeki sorunlardan veya sosyal destek yetersizliklerinden de kaynaklanabildiği belirtilmektedir (3). Hasta ve hemşirelerin iletişimlerini ve iletişimde yaşanan sorunları inceleyen çalışmalar incelendiğinde, problemlerin büyük çoğunluğunun ilişkide sorun yaratabilen bazı hasta davranışlarından ve bu davranışlar karşısında hemşirelerin duygularını kontrol etmede yaşadıkları yetersizliklerden kaynaklandığı saptanmıştır (5, 7-9). Hemşireleri en çok zorlayan hasta davranışlarının; iletişim kurmayan, sürekli isteklerde bulunan, ikincil kazanç sağlama peşinde olan, tehlikeli, agresif, öfkeli, ilgi bekleyen, ağlayan, sağlık ekibi ile iş birliği yapmayan, cinsel içerikli davranışları olan, kurallara karşı koyan, yalan söyleyen, korkmuş, inatçı, kafası karışmış, kışkırtıcı, kırıcı, hijyeni kötü olan, bakım ve tedavilerini ret eden, hastalığını inkâr etme gibi davranışlar olduğu belirtilmektedir (1, 10). İletişimi zorlayan hastalar karşısında hemşireler, birçok karmaşık duyguyu bir arada yaşamakta ve farklı iletişim davranışları sergileyebilmektedirler. Hemşireler, bu tür davranışlar karşısında sıklıkla sakinliklerini kaybedebilmekte ve sonuç olarak öfkelerini kontrol etmede zorluk yaşayabilmektedirler. Ayrıca yetersizlik duygusu, suçluluk duygusu, kendilerini üzgün, sinirli ve çaresiz hissetme, değersizlik duygusu, hayal kırıklığı gibi negatif duygularda hemşirelerin en yoğun hissettikleri duygular arasında yer almaktadır (5).
Hemşirelerin iletişim becerileri kadar iletişimlerini zorlayan hastalar karşısında yaşadıkları en yoğun duygu öfkedir ve hemşirelerde öfke duygusu ile baş etme becerilerinin geliştirilmesi oldukça önemlidir (11). Özellikle hastanelerin dâhiliye ve cerrahi gibi genel klinikleri sayı bakımından hemşirelerin en fazla istihdam edildikleri kliniklerdir. Yoğun bakımlardan farklı olarak bu kliniklerde tedavi gören hastalar sağlık çalışanı ile sürekli iletişim halindedir. Bu sebeple özellikle bu kliniklerde çalışan hemşirelerin iletişim becerileri ve öfke kontrolü konusunda daha deneyimli olmaları gerekmektedir. Kliniklerde yaşanan hasta-hemşire çatışmalarının çoğunlukla iletişim kazalarından kaynaklandığı ve öfkesini doğru kontrol edebilen hemşirelerin bu çatışmaları profesyonel bir şekilde çözebildiği ve hastasının bakımına da olumlu yönde destek sağlayabildiği bilinmektedir. Öfke ve öfkeyi ifade etme biçiminin, kişilerarası ilişkiler, ruhsal ve fiziksel sorunlar üzerinde önemli bir etkisi bulunmaktadır (12). Yapılan çalışmalar incelendiğinde kontrol edilemeyen öfke duygusunun sağlık çalışanlarının iş doyumunu, bakım kalitesini, sosyal ilişkilerini ve tükenmişlik seviyelerini olumsuz yönde etkilediği belirlenmiştir (11, 13-15). Bu çalışma, hemşirelerin iletişim becerileri ve öfke yönetimlerinin belirlenmesi amacı ile gerçekleştirilmiştir.

\section{Gereç ve Yöntem}

\section{Araştırmanın tipi}

Bu çalışma, Ankara ilinde yer alan bir eğitim ve araştırma hastanesinin dâhiliye ve cerrahi kliniklerinde çalışan hemşirelerin iletişim becerileri ve öfke yönetimlerinin belirlenmesi amacı ile Mart - Haziran 2017 tarihleri arasında tanımlayıcı olarak yapılmıştır.

\section{Çalışmanın evreni ve örneklemi}

Çalışmanın evrenini, eğitim ve araştırma hastanesinin dâhiliye ve cerrahi kliniklerinde çalışan toplam 385 hemşire oluşturmuştur. Çalışmaya katılmayı kabul eden ve onam veren 144 hemşire çalışmaya dâhil edilmiştir.

\section{Çalışmanın etik onayı}

Ankara Yıldırım Beyazıt Üniversitesi (AYBÜ) Sosyal ve Beşeri Bilimler Etik Kurulu (SBEK) tarafından onay alındıktan sonra araştırmanın yapılacağı eğitim ve araştırma hastanesinin bağlı bulunduğu genel sekreterlik ve hastanın bakım hizmetleri müdürlüğünden gerekli olan izinler yazılı olarak alınmıştır.

\section{Çalışmanın verilerinin toplanması}

Çalışmada veriler, araştırmacı tarafından geliştirilen "sosyo-demografik özellikler veri toplama formu", "Sürekli Öfke ve Öfke İfade Tarzı Ölçeği" ve "İletişim Becerileri Envanteri" kullanılarak ve yüz yüze görüşme yöntemiyle toplanmıştır. 
Sosyo-demografik Özellikler Veri Toplama Formu: Hemşirelerin sosyo-demografik özellikleri ve mesleki deneyimlerini belirlemeye yönelik olarak literatürden elde edilen bilgiler ışı̆̆ında araştırmacı tarafından geliştirilmiştir. Toplam 11 sorudan oluşan bu formda hemşirelerin yaşı, medeni durumu, eğitim durumu ve toplam çalışma süreleri gibi özellikleri sorgulanmıştır.

Sürekli Öfke ve Öfke İfade Tarzı Ölçeği (SööTö): Özgün ismi, "The State-Trait Anger and Anger Expression Scale" olan ve 1983 yılında Spielberger, Jacobs, Russel ve Crane tarafından geliştirilen ölçeğin Türkçe geçerlilik ve güvenirlilik çalışması Kadir Özer tarafından yapılmıştır (17). Toplam 34 maddeden oluşan ölçek dörtlü Likert tekniği ile değerlendirilmektedir $(17,18)$. Bireyin değerlendirilmesinde kendisi için uygun gelen ifadelerden "sizi ne kadar tanımlıyor?" sorusuna yanıt olacak şekilde "hiç tanımlamıyor" yanıtından 1 puan, "biraz tanımlıyor" yanıtından 2 puan "oldukça tanımlıyor" yanıtından 3 puan ve "tümüyle tanımlıyor" yanıtından 4 puan elde edilir. Ölçekte ilk 10 madde sürekli öfke puanını verirken öfke ifade alt ölçeğinde 13, 15, 16, 20, 23, 26, 27 ve 31 nolu maddeler içe yöneltilen öfke puanlarını, 12, 17, 19, 22, 24, 29, 32 ve 33 nolu maddeler dışa yöneltilen öfke puanlarını ve 11, 14, 18, 21, $25,28,30$ ve 34 nolu maddeler ise öfke kontrol puanlarını vermektedir. Sürekli öfke ölçeğinden alınan yüksek puanlar öfke düzeyinin yüksek olduğunu, Kontrol öfke ölçeğinden alınan yüksek puanlar öfkenin kontrol edilebildiğini, Öfke Dışa ölçeğinden alınan yüksek puanlar öfkenin kolayca dışa yöneltilebildiğini ve Öfke İçe Alt ölçeğinden alınan yüksek puanlar ise öfkenin bastırılmış olduğunu ifade etmektedir (19). Ölçeğin Cronbach alfa katsayısı sürekli öfke için $a=0,89$; öfke dışta için $a=0,89$; öfke içte için $a=0,75$ ve öfke kontrol için $a=0,92$ olarak bulunmuştur (18). Grup ya da bireysel olarak uygulanabilen ölçek, 13 yaşından itibaren ergenler ve yetişkinlerde kullanılabilmektedir.

İletişim Becerileri Envanteri (IBBE): Balcı ve Ersanlı (1998) tarafından üniversite öğrencilerinin iletişim beceri düzeylerini ölçmek amacıyla geliştirilmiştir (20). Ölçek davranışsal, bilişsel ve duygusal olmak üzere üç alt boyuttan oluşmaktadır. Ölçek toplam 45 maddeden oluşmaktadır. 1, 3 , $6,12,15,17,18,20,24,28,30,33,37,43,45$ maddeler zihinsel alt boyut puanlarını, 5, 9, 11, 26, 27, 29, 31, 34, 35, 36, $38,39,40,42,44$. maddeler duygusal alt boyut puanlarını, $2,4,7,8,10,13,14,16,19,21,22,23,25,32,41$. maddeler ise davranışsal alt boyut puanlarını vermektedir. Ölçeğin $3,5,9,10,11,16,23,24,27,29,31,32,34,35,37,41,42$ maddeleri ters olarak puanlanmaktadır. Her alt boyut ayrı ayrı değerlendirileceği gibi ölçeğin toplam puanına bakılarak bireyin genel iletişim beceri düzeyi hakkında bilgi edinilebilir. Ölçek 5'li likert tipinde geliştirilmiştir. Ölçeğe verilen tepkiler; her zaman (5), genellikle (4), bazen (3), nadiren (2), hiçbir zaman (1) şeklinde düzenlemiştir $(20,21)$.

\section{Bulgular}

Çalışmaya katılan hemşirelerin tamamı kadın olup \%44,4 $(n=64)^{\prime}$ ü 30-39 yaş aralığında, \%66,7 ( $\left.n=96\right)$ 'si evli ve $\% 35,4$ ( $n=51$ )'ünün iki çocuğu vardır. \%59,7 ( $n=86)$ hemşirenin gelirleri ile giderlerinin eşit olduğu belirlenmiştir. Eğitim durumları incelendiğinde, \%72,9 ( $n=105)^{\prime} u$ lisans, diğerleri yüksek lisans derecesine sahiptir. \%70,8 ( $n=102)$ hemşire hem gece hem gündüz vardiyasında çalışmakta olup, \%44,4 ( $n=64)^{\prime}$ ü ayda 24 saat ve üzeri nöbet tuttuğu saptanmıştır. Hemşirelerin \%67,4 (n=97)'ü çalıştıkları klinikten memnun olduklarını belirtmiştir.

Hemşirelerin SÖÖTÖ ve alt ölçek puan ortalamalarının dağılımı Tablo 1'de görülmektedir. Sürekli öfke puan ortalamaları $17,18 \pm 4,11$; içe yöneltilen öfke puan ortalamaları 14,54 $\pm 2,92$; dışa yöneltilen öfke puan ortalamaları $13,50 \pm 2,98$ ve öfke kontrolü puan ortalamaları da $21,36 \pm 3,74$ olarak belirlenmiştir.

Hemşirelerin İBE ve alt ölçek puan ortalamalarının dağıIımı Tablo 2'de görülmektedir. İletişim toplam puan ortalamaları 161,74 $\pm 13,71$; zihinsel alt boyut puan ortalamaları 55,81 $\pm 5,99$; duygusal alt boyut puan ortalamaları $52,72 \pm 5,34$ ve davranışsal alt boyut puan ortalamaları da $53,20 \pm 4,98$ olarak belirlenmiştir.

Tablo 1. Hemşirelerin SÖÖTÖ alt ölçek puan ortalamaları

\begin{tabular}{lccc} 
Ölçekler & $\boldsymbol{X} \pm \boldsymbol{S D}(\boldsymbol{n = 1 4 4 )}$ & $\boldsymbol{M i n}(\mathbf{m i n}) *$ & Max (maks)* \\
\hline Sürekli öfke & $17,18 \pm 4,11$ & $10(10)$ & $31(40)$ \\
Öfke içte & $14,54 \pm 2,92$ & $9(8)$ & $24(32)$ \\
Öfke dışta & $13,50 \pm 2,98$ & $8(8)$ & $25(32)$ \\
Öfke kontrol & $21,36 \pm 3,74$ & $8(8)$ & $32(32)$ \\
\hline
\end{tabular}

$\mathrm{X} \pm \mathrm{SD}$, ortalama \pm standart sapma; Min, minimum; Max, maksimum

Tablo 2. Hemşirelerin IBE ve alt ölçek puan ortalamaları

\begin{tabular}{lccc} 
Ölçekler & $\boldsymbol{X} \pm \boldsymbol{S D}(\boldsymbol{n = 1 4 4 )}$ & ${\text { Min }(\mathbf{m i n})^{*}}^{*}$ & Max (maks)* \\
\hline $\begin{array}{l}\text { Iletişim becerileri } \\
\text { envanteri }\end{array}$ & $161,74 \pm 13,71$ & $113(45)$ & $184(225)$ \\
Zihinsel alt boyut & $55,81 \pm 5,99$ & $35(15)$ & $66(75)$ \\
Duygusal alt boyut & $52,72 \pm 5,34$ & $33(15)$ & $64(75)$ \\
Davranışsal alt boyut & $53,20 \pm 4,98$ & $40(15)$ & $65(75)$ \\
\hline
\end{tabular}

$\mathrm{X} \pm \mathrm{SD}$, ortalama \pm standart sapma; Min, minimum; Max, maksimum 
Hemşirelere uygulanan SÖÖTÖ ve IBE ölçeklerinin korelasyon tablosu Tablo 3'te görülmektedir. İki ölçek arasındaki ilişkiye bakıldığında hemşirelerin iletişim toplam puanları ve zihinsel, duygusal ve davranışsal alt boyutları ile sürekli öfke, öfke içte ve öfke dışta puanları arasında negatif yönlü ve istatistiksel olarak anlamlı bir ilişki belirlenmiştir. Öfke kontrol puanları ile ise pozitif yönlü ve anlamlı bir ilişki saptanmıştır $(p<0,001)$.

\begin{tabular}{|c|c|c|c|c|c|}
\hline & & Sürekli öfke & Öfke içte & Öfke dışta & Öfke kontrol \\
\hline İBE & $\begin{array}{l}r \\
p\end{array}$ & $\begin{array}{c}-0,396^{\star *} \\
0,000\end{array}$ & $\begin{array}{c}-0,298^{* *} \\
0,000\end{array}$ & $\begin{array}{c}-0,394^{* *} \\
0,000\end{array}$ & $\begin{array}{c}0,362^{* *} \\
0,000\end{array}$ \\
\hline Zihinsel & $\begin{array}{l}r \\
p\end{array}$ & $\begin{array}{c}-0,369 * * \\
0,000\end{array}$ & $\begin{array}{c}-0,224^{\star \star} \\
0,007\end{array}$ & $\begin{array}{c}-0,374^{\star \star} \\
0,000\end{array}$ & $\begin{array}{c}0,355^{\star *} \\
0,000\end{array}$ \\
\hline Duygusal & $\begin{array}{l}r \\
p\end{array}$ & $\begin{array}{c}-0,284^{* *} \\
0,001\end{array}$ & $\begin{array}{c}-0,247^{* *} \\
0,003\end{array}$ & $\begin{array}{c}-0,325^{\star \star} \\
0,000\end{array}$ & $\begin{array}{c}0,235^{\star *} \\
0,005\end{array}$ \\
\hline Davranışsal & $\begin{array}{l}r \\
p\end{array}$ & $\begin{array}{c}-0,339 * * \\
0,000\end{array}$ & $\begin{array}{c}-0,284^{\star *} \\
0,001\end{array}$ & $\begin{array}{c}-0,285^{\star *} \\
0,001\end{array}$ & $\begin{array}{c}0,316^{* *} \\
0,000\end{array}$ \\
\hline
\end{tabular}

IBE, iletişim becerileri envanteri; $\mathbf{r}$, Pearson korelasyon analizi; $\mathbf{p}$, önemlilik.

\section{Tartışma}

Hemşirelik mesleğinde en önemli faktörlerden birisi, hemşirenin iletişim becerilerini etkili bir şekilde kullanabilmesi, hastayı doğru bir şekilde anlayabilmesi ve sonrasında da anlatmak istediklerini hastasına doğru bir şekilde ifade edebilmesidir. Burada, en önemli etmenler hemşirenin kendini tanıması, güçlü ve zayıf yönlerinin farkında olabilmesidir (19). İletişim, birçok meslekte olduğu gibi hemşirelik mesleği için de tüm süreçlerin temelini oluşturmaktadır (15). Çalışmamızın sonuçlarında hemşirelerin iletişim becerileri envanterinden aldıkları toplam puanların, farklı meslek grupları ile yapılan çalışma sonuçlarına göre daha yüksek olduğu saptanmıştır (22-24). Bu konuda yapılan çalışmalarda da hemşirelerin iletişim beceri puanları bizim çalışmamızın sonuçları ile benzer şekilde yüksek bulunmuştur (15, 25-28). Hemşirelerin iletişim beceri puanlarının diğer meslek gruplarına göre yüksek olması, çalışmaya katılan hemşirelerin lisans ve yüksek lisans mezunu olmaları hem üniversite eğitimlerinde hem de mesleğe başladıktan sonra düzenli olarak hizmet içi eğitimlerle iletişim derslerini alıyor olmalarından kaynaklandığı düşündürmüştür. Akgün Şahin ve ark. (2015) yaptıkları çalışmada hemşirelerin eğitim düzeyi yükseldikçe iletişim puanlarının arttığını saptamışlar ve bu durumu üniversitelerde eğitim sürecinde verilen empati ve iletişim becerisine ait derslere önem verilmesine bağlamışlardır (21).

Öfke ifadesi insanın içinde bulunduğu gerginliği ve stresi dışa yansıtma biçimlerinden olup, stresli iş ortamında çalışan hemşirelerin profesyonel tutumları ve hemşirelik bakım davranışlarını, ayrıca terapötik iletişim becerilerini olumsuz yönde etkileyebilmektedir (29). Son yıllarda artan teknoloji ve gelişmeler ile birlikte hastaların beklentilerinde de artış söz konusudur. Bu durum, hastane ortamlarında rekabetin yanında, stresli çalışma ortamını ortaya çıkarmaktadır (kaynak ekle). Stresin yoğun olduğu ortamlarda yaşanan en yoğun duygu ifadesi, öfke olmaktadır (16). Çalışmamızın sonuçlarına bakıldığında hemşirelerin sürekli öfke ve öfke ifade tarzı ölçeğinden aldıkları puanların ortalamaları, hemşireler ve hemşirelik öğrencileri ile yapılan farklı çalışma sonuçları ile benzerlik göstermektedir $(11,14,21,29,30)$. Çalışmamızın bulguları incelendiğinde, hemşirelerin sürekli öfke puan ortalamalarının içe atılan öfke ve dışa vurulan öfke puan ortalamalarına göre daha yüksek olduğu, en yüksek puan ortalamasının ise öfke kontrol puanı olduğu bulunmuştur. Kocatepe ve ark. (2017)'nın, Baran ve Okanlı (2015)'nın, Kaya ve ark. (2012)'nın, Yıldırım ve ark. (2009)'nın yaptıkları çalışmalarda da bizim çalışmamız ile paralel sonuçlar belirlenmiş̧ir $(11,14,16,31)$. Hemşirelik mesleği, sağlık hizmetine gereksinimi olan bireylere ve onların yakınlarına kesintisiz olarak hizmet veren tek sağlık disiplinidir. Özellikle, yatan hastaların bulunduğu yataklı servislerde hasta bireyin ve yakınının en kolay ulaşabildiği sağlık ekibi üyesi hemşirelerdir. Bu zor ve yorucu sorumluluk durumundaki hemşireler sürekli öfke duygusu yaşamaktadır (14). Hemşirelerin sürekli öfke puan ortalamalarının diğer alt ölçek puanlarına göre daha yüksek olmasının, bu duruma bağlı olabileceği düşülmektedir. Yoğun iş temposuna karşılık sahip oldukları mesleki felsefeleri ve değerleri, lisans eğitimlerinde iletişim ve öfke kavramlarının titizlikle ele alınıyor olması nedeni ile öfke kontrol puan ortalamalarının ise diğer alt ölçek puan ortalamalarına göre daha yüksek olduğu düşünülmektedir.

IBE ile SÖÖTÖ arasındaki ilişki incelendiğinde, negatif ve istatistiksel olarak anlamlı bir ilişki olduğu görülmektedir. Yani, hemşirelerin iletişim becerileri ve alt ölçek puanları arttıkça öfke kontrollerinin arttığı, sürekli öfke, öfke dışta ve öfke içte puanlarının ise düştüğü söylenebilir. Kutlu ve Albayrak (2009) ergenler ile yaptıkları çalışmalarında arkadaşları ile iletişimi iyi olan ergenlerin öfke içte puanlarının düşük olduğunu belirtmişlerdir (32). Han ve ark. (2015)'nın çalışmalarında hemşirelerin öfke biçimleri ile yaşadıkları kişilerarası problemleri incelemişler ve çalışmalarının sonucunda öfke kontrol problemi olan ve öfke içte puanları yüksek olan hemşirelerin daha fazla kişiler arası problem yaşadıklarını belirtmişlerdir (29). Tatlıoğlu ve Karaca (2013)'nın ifade ettikleri gibi öfke ile hareket etmenin aynı zamanda etkili iletişim imkânını yok ederek 
iletişim çatışmalarına yol açtığını ve çatışmaları daha da büyütebildiğini bildirmişlerdir (33). Bu görüşler, bizim çaıışmamızın sonuçlarını desteklemektedir.

Sonuç olarak hemşirelerin iletişim becerilerinin ortalamanın üzerinde olduğu, sürekli öfke durumlarının içe atılan öfke ve dışa vurulan öfke davranışlarından daha belirgin olduğu, öfke kontrollerini sağlamada diğer öfke yönetim

\section{Kaynaklar}

1. Göral G. Hemşirelik ve Tıp Öğrencilerinin Zor Hasta Algısı ve Zor Hasta ile İletişimlerinin Belirlenmesi. Sağlık Bilimleri Enstitüsü Ruh Sağlığı ve Psikiyatri Hemşireliği Anabilim Dalı, Yüksek Lisans Tezi, Antalya: Akdeniz Üniversitesi 2011.

2. Velioğlu P. Hemşirelikte Kavram ve Kuramlar. İstanbul: Akademi Basın ve Yayıncilık; 2012. ss.271-81.

3. Özcan A. Hemşire Hasta İlişkisi ve İletişim. Ankara: Sistem Ofset Bas. Yay. San. Tic.; 2012.

4. Yalçın N, Aştı T. Hemşire-Hasta etkileşimi. İ. Ü. F. N. Hem Derg 2011;19:54-9.

5. Akgün Çıtak E, Avcı S, Basmacı Ö, Durukan İ. Bir üniversite hastanesinde hemşirelerin "zor hasta" olarak tanımladıkları hastalarla iletişim davranışlarının incelenmesi. HEMAR-G 2011;13:35-44. http://hemarge.org.tr/ckfinder/userfiles/files/2011/2011-vol13sayi1-130.pdf

6. Gorman LM, Sultan DF, Raines ML. Nurses Responses to Difficult Patient Behaviors. In: Gorman LM, Sultan DF, Raines ML, editors. Davis's Manual of Psychosocial Nursing in General Patient Care. Philadelphia: F. A. Davis Company; 1996. pp.39-51.

7. Wolf ZR, Robinson-Smith G. Strategies used by clinical nurse specialists in "difficult" clinician- patient situations. Clin Nurse Spec 2007;21:74-84. [CrossRef]

8. Macdonald M. Origins of Difficulty in the Nurse-Patient Encounter. Nurs Ethics 2007;14:510-21. [CrossRef]

9. Sheldon LK, Barrett R, Ellington L. Difficult Communication in Nursing. J Nurs Scholarsh 2006;38:141-7. [CrossRef]

10. Koekkoek B, van Meijel B, Hutschemaekers G. "Difficult Patients" in mental health care: a review. Psychiatr Serv 2006;57:795-802. [CrossRef]

11. Baran M, Okanlı A. Hemşirelerin öfke düzeyinin iş doyumuna etkisi. Anadolu Hemşirelik ve Sağlık Bilimleri Dergisi 2015;18:43-9. [CrossRef]

12. Akdeniz M. Öfke kontrolü eğitiminin lise öğrencilerinin öfke kontrolü becerilerine etkisi. Sosyal Bilimler Enstitüsü, Eğitim Bilimleri Anabilim Dalı, Yüksek Lisans Tezi, Adana: Çukurova Üniversitesi, 2007.

13. Kart ME. Acil Serviste Kadın Hemşire Olmak: Tükenmişlik Sendromunda Öfke Duygusunun Rolü. İçinde: Kurt S, Alp S, Çapar S, editörler. 21. yy Eşiğinde Kadınlar, Değişim ve Güçlenme. Uluslararası Multidisipliner Kadın Kongresi Bildiri Kitabı. İzmir: Dokuz Eylül Üniversitesi Fen-Edebiyat Fakültesi Yayını 2010. ss.147-57.

14. Kaya N, Kaya H, Yalçın Atar N, Turan N, Eskimez Z, Palloş A, Aktaş A. Hemşirelik ve Ebelik Öğrencilerinin Öfke ve Yalnızlık Özellikleri. HEAD 2012;9:18-26. https://www.journalagent.com/kuhead/pdfs/ KUHEAD_9_2_18_26.pdf

15. Duran S, Karadaş A, Kadder E. Hemşirelik öğrencilerinin tolerans düzeyleri ile öfke kontrolleri arasındaki ilişkinin incelenmesi. SDÜ Sağlık Bilimleri Enstitüsü Dergisi 2016;7:39-44. becerilerine göre daha başarılı oldukları belirlenmiştir. Hemşirelerin iletişim becerileri geliştikçe öfke yönetiminde de daha başarılı olacakları değerlendirilmektedir. Bu sonuçlar doğrultusunda, hemşirelere düzenli aralıklar ile iletişim becerileri ve öfke yönetimi eğitiminin verilmesinin hemşirelerin öfkelerini uygun bir şekilde yönetebilmelerine katkı sağlayacağı ve yaşanan iletişim kazalarını en aza indirilebileceği düşünülebilir.

16. Kocatepe V, Uğur E, Karabacak Ü. Yoğun Bakım ve Palyatif Bakım Ünitelerinde Çalışan Hemşirelerin Sürekli Öfke ve Öfke İfade Tarzları ile Bakım Davranışları Arasındaki İlişki. F. N. Hemşirelik Dergisi 2017;25:13-20. [CrossRef]

17. Özer AK. Sürekli Öfke (SL-Öfke) ve Öfke Iffade Tarzı (Öfke-Tarz) ölçekleri ön çalışması. Türk Psikoloji Dergisi 1994;9:26-35. https:// toad.halileksi.net/sites/default/files/pdf/ofke-ifade-tarzi-ofke-tarzolcegi-toad.pdf

18. Avcı D. Bilişsel davranışçı tekniklere dayalı öfke ile baş etme programının ergenlerin ruh sağlığına etkisi. Sağlık Bilimleri Enstitüsü, Psikiyatri Hemşireliği Anabilim Dalı, Doktora Tezi, Sivas: Cumhuriyet Üniversitesi, 2012.

19. Kumcağız H, Yılmaz $M$, Çelik SB, Avcı IA. Hemşirelerin İletişim Becerileri: Samsun ili Örneği. Dicle Tıp Dergisi 2011;38:49-56. http:// diclemedj.org/upload/sayi/13/Dicle\%20Med\%20J-01245.pdf

20. Ersanlı K, Balcı S. İletişim becerileri Envanteri Geçerlilik ve Güvenirlilik Çalışması. Türk Psikolojik Danışma ve Rehberlik Dergisi 1998:2:7-12. https://toad.halileksi.net/sites/default/files/pdf/iletisim-becerilerienvanteri-toad.pdf

21. Akgün Şahin Z, Kardaş Özdemir F. Hemşirelerin iletişim ve empati beceri düzeylerinin incelenmesi. G. O. P. Taksim E. A. H. JAREN 2015;1:1-7. [CrossRef]

22. Örücü $E$, Kıvrak O. Telekomünikasyon sektöründe çalışan personelin Iletişim Becerileri Düzeylerinin İncelenmesi. Yönetim ve Ekonomi 2013;20;15-29. http://www.acarindex.com/dosyalar/makale/ acarindex-1423938822.pdf

23. Yıldız Y, Kurtuldu K. Müzik Öğretmeni Adaylarının İletişim Becerilerinin İncelenmesi: Karadeniz Teknik Üniversitesi Örneği. Route Educational and Social Science Journal 2016;3:208-17.

24. Dallı $M$, Ünlü $Y$, Pekel $A$. Spor yöneticiliği bölümü öğrencilerinin iletişim beceri düzeyleri ile girişimcilik düzeyleri arasındaki ilişki. Akademik Sosyal Araştırmalar Dergisi 2017;5:28-34. [CrossRef]

25. Kaya N, Turan N, Kamberova HA, Cenal Y, Kahraman A, Evren M. Hemşirelik Öğrencilerinin Sanat Özelliklerine Göre Illetişim Becerileri ve Sosyal Zeka Düzeyleri. HEAD 2016;13:50-8. [CrossRef]

26. Karadağ $M$, Işık $O$, Cankul iH, Abuhanoğlu H. Hekim ve Hemşirelerin İletişim Becerilerinin Değerlendirilmesi. Gazi Üniv I I B F Dergisi 2015;17;160-79.

27. Şen HT, Yılmaz FT, Ünüvar ÖP. Hizmet içi eğitim hemşirelerinin iletişim beceri düzeyleri. Psikiyatri Hemşireliği Dergisi 2013;4:13-20. [CrossRef]

28. Kaya F. Hemşirelerin İletişim ve Empatik Beceri Düzeyleri ile Hastaların Hemşirelik Bakımını Algılayışlarının Karşılaştıııması, Sağlık Bilimleri Enstitüsü Hemşirelik Anabilim Dalı, Yüksek Lisans Tezi, Mersin: Mersin Üniversitesi, 2011.

29. Han A, Won J, Kim O, Lee SE. Anger Expression Types and Interpersonal Problems in Nurses. Asian Nurs Res (Korean Soc Nurs Sci) 2015;9:146-51. [CrossRef] 
30. Ata EE, Akpınar Ş, Kelleci M. Üniversite öğrencilerinin problemli internet kullanımı ile öfke ifade tarzları arasındaki ilişki. TAF Prev Med Bull 2011;10:473-80. [CrossRef]

31. Yıldırım A, Karakurt P, Hacıhasanoğlu R. Comparison of the problem solving skills with feeling and expression of anger in nursing students. Atatürk Üniversitesi Hemşirelik Yüksekokulu Dergisi 2009;12:57-65.
32. Albayrak B, Kutlu Y. Ergenlerde öfke ifade tarzı ve ilişkili faktörler. Maltepe Üniversitesi Hemşirelik Bilim ve Sanatı Dergisi 2009;2:57-69. http://openaccess.maltepe.edu.tr/xmlui/ bitstream/handle/20.500.12415/3587/Banu\%20Albayrak. pdf? sequence $=1 \&$ isAllowed $=y$

33. Tatlilioğlu K, Karaca M. Öfke Olgusu Hakkında Sosyal Psikolojik Bir Değerlendirme. Int J Soc Sci 2013;6:1101-23. [CrossRef] 